20

21

\title{
Multilocus sequence typing of Cronobacter spp. from powdered infant formula and milk powder production factories
}

\section{4}
Hana Sonbol $^{\mathrm{a}}$, Susan Joseph ${ }^{\mathrm{a}}$, Catherine M. McAuley ${ }^{\mathrm{b}}$, Heather M. Craven ${ }^{\mathrm{b}}$, and Stephen J. Forsythe $^{\mathrm{a}^{*}}$

\section{a Pathogen Research Centre, School of Science and Technology, Nottingham Trent} University, Clifton Lane, Nottingham, UK. NG11 8NS

${ }^{\mathrm{b}}$ CSIRO Animal, Food and Health Sciences, Werribee, Vic., Australia

2 'Corresponding author. Mailing address: Prof SJ Forsythe, School Science and Technology,

2 Nottingham Trent University, Clifton Lane, Nottingham, NG11 8NS, UK. Phone: 0115

23 8483529. Fax: 0115 8486636. E-mail: stephen.forsythe@ntu.ac.uk. 
25 Abstract

26 This study applied the Cronobacter spp. multilocus sequence typing (MLST) scheme to three

27 strain collections, then known as Enterobacter sakazakii, which had been isolated between

281988 and 2009 from 14 countries. The results revealed the predominance (85\%) of $C$.

29 sakazakii (72 strains) in all three collections. The remaining strains were $C$. turicensis (10\%),

30 C. malonaticus (4\%), and $C$. muytjensii (1\%). No strains of $C$. dublinensis, $C$. universalis or $C$.

31 condimenti were identified. Twenty-one out of seventy two $C$. sakazakii strains were in the

32 clinically significant ST4 clonal complex, and were found in all three strain collections. These

33 results confirm C. sakazakii ST4 is one of the predominant clonal complexes over the past 20

34 years in several parts of the world. Further understanding of the ecosystem and sources of

35 the organism may be used for the development of improved intervention strategies in the

36 diary industry.

37 


\section{Introduction}

Cronobacter spp. (formerly known as Enterobacter sakazakii) is a diverse genus in the family Enterobacteriaceae. It is composed of seven species; $C$. sakazakii, $C$. malonaticus, $C$. muytjensii, $C$. turicensis, $C$. dublinensis, $C$. universalis, and $C$. condimenti (Iversen et al., 2007; Joseph et al., 2012a). Three of these species have been isolated from neonatal infections: $C$. sakazakii, C. malonaticus, and C. turicensis (Forsythe, 2005; Joseph et al., 2012c). Whole genome sequencing of all seven species has revealed that the organism encodes a range of virulence traits comprising of adhesins, phage sequences, type four and six secretion systems, multidrug efflux systems, and a range of iron acquisition genes (Joseph et al., 2012b; Kucerova et al., 2010).

Although the majority of Cronobacter spp. infections are in adults (FAO/WHO, 2008), this bacterial genus has come to the attention of regulatory authorities and the public due to its association with severe neonatal infections (Bowen \& Braden, 2006; Codex Alimentarius Commission, 2008). Such infections have a high fatality rate, of 40 to $80 \%$, and survivors often suffer from severe neurological disorders (Caubilla-Barron et al., 2007; Lai, 2001; van Acker, de Smet, Muyldermans, Bougatef, \& Naessens, 2001). Epidemiological studies of outbreaks in neonatal intensive care units led to the recognition of reconstituted powdered infant formula (PIF) as a route of infection (Himelright, Harris, Lorch, \& Anderson, 2002; van Acker et al., 2001).

A multilocus sequence typing (MLST) curated database has been established for the entire Cronobacter genus and has open access at http://www.pubMLST.org/cronobacter (Baldwin, et al., 2009; Joseph \& Forsythe, 2012; Joseph et al., 2012c). The scheme is based on seven housekeeping genes ( $a t p D, f u s A, g \ln S, g / t B, g y r B, \inf B, p p s A)$ with a concatenated length of 3036 nucleotides that can be used for phylogenetic analysis. The Cronobacter MLST scheme has been applied to over 400 isolates. There are currently 136 defined sequence types (ST), with 55 STs in C. sakazakii (Joseph \& Forsythe, 2012; Joseph et al., 2012c). Recently, Joseph and Forsythe (2011) compared C. sakazakii ST profiles with severity of infection by compiling patient details, isolation site and clinical presentation for strains isolated from around the world up to 2008. C. sakazakii ST1 strains are primarily isolates from infant formula, whereas $C$. sakazakii ST8 is primarily composed of isolates from clinical sources. Of 
special significance is $C$. sakazakii ST4 which has a high propensity for neonatal meningitis (Joseph \& Forsythe, 2011; Joseph et al., 2012c). This appears to be a very stable lineage as clinical and non-clinical ST4 strains have been isolated from seven countries for over 50 years. This retrospective association was supported in December 2011 in the US with highly publicised Cronobacter neonatal infection cases (Centers for Disease Control and Prevention, 2012), in which C. sakazakii ST4 was isolated from the neonatal meningitis cases (Hariri, Joseph, \& Forsythe, 2012). In addition, C. malonaticus ST7 is associated with adult infections though the source has not been identified (Joseph \& Forsythe, 2011; Joseph et al., 2012c).

Although its presence in PIF fed to newborn babies has attracted the most attention, Cronobacter spp. have been isolated from foods such as cheese and meat and from hospital environments including air, formula-mixing utensils, and enteral feeding tubes (Hurrell et al., 2009; Kucerova, Joseph, \& Forsythe, 2011).

Many studies have shown that Cronobacter spp. can be isolated from milk powder and PIF manufacturing facilities (Craven, McAuley, Duffy, \& Fegan, 2010; Jacobs, Braun, \& Hammer, 2011; Mullane, Whyte, Wall, Quinn, \& Fanning, 2007). The organism may persist in these environments due to its ability to survive spray drying, desiccation, and osmotic stress (Arku, Mullane, Fox, Fanning, \& Jordan, 2008; Breeuwer, Lardeau, Peterz, \& Joosten, 2003; Osaili \& Forsythe, 2009). Cronobacter spp. have been shown to survive more than two years in desiccated PIF (Caubilla-Barron \& Forsythe, 2007). Mullane et al. (2007) used pulsed-field gel electrophoresis (PFGE) to profile Cronobacter spp. isolates from a production site, and demonstrated the persistence of specific bacterial clones in the industrial facilities, and periodically these could be isolated from air samples. Minimising the presence of Cronobacter spp. in milk powder production facilities is achieved by environment control including zoning to physically separate high and low hygiene areas, maintaining a low moisture environment (reducing water ingress), effective cleaning routines and control of dust and waste powder. Together these reduce the survival, growth and colonization opportunities for the organism (Cordier, 2008). Nevertheless, PIF should not be considered a sterile product.

In the 1980's, Muytjens et al. (1983) and Muytjens, van Der Ros-van de Repe, \& van Druten (1984) reported several cases of $E$. sakazakii infection in neonates, which could be linked to 
contaminated milk powders (these days more commonly known as PIF) and preparation equipment. The group undertook an international survey of PIF for the presence of Enterobacteriaceae, which were identified phenotypically. They isolated E. sakazakii from 20 out of 141 (14.2\%) PIF samples from 35 countries (Muytjens, Roelofs-Willemse, \& Jaspar, 1988). This highly cited study was used in the FAO/WHO risk assessments of $E$. sakazakii in PIF (FAO/WHO, 2004, 2006, 2008). However, given this seminal work was before the 2007 taxonomic revision, the strains lack Cronobacter species attribution, therefore genotyping the strains would considerably increase the value of these older studies. In addition, Townsend, Hurrell, Caubilla-Barron, Loc-Carrillo, and Forsythe (2008) reported that one of the strains of Muytjens et al. (1988) was a mis-identified strain of E. hormaechei. Therefore the reinvestigation of the available strains is warranted using MLST to assign the Cronobacter species and sequence types (STs).

Similarly, this study has determined the Cronobacter species and STs of isolates from two studies of six milk powder processing factories (Craven et al., 2010; Jacobs et al., 2011). The isolates had not been identified at the Cronobacter species level as, despite the year of publication, they had been isolated and identified before the taxonomic revision. Craven et al. (2010) identified 49 E. sakazakii pulsetypes, according to Xbal restriction digestion, representing 126 isolates from 100 locations in the non-processing and processing environments of five milk powder factories in Australia. These had been sampled between November 2006 and March 2007. In addition, three strains could not be profiled by PFGE. Jacobs et al. (2011) analysed environmental and final product samples from a milk powder manufacturing plant over a four year period (2005-2009) in Germany. Eighty-one $E$. sakazakii strains were isolated from the spray-drying area and the roller-drying area. These were divided into 13 pulsetypes, following PFGE analysis with Xbal restriction digestion. This study applied MLST to these previously published sets of strains, then known as $E$. sakazakii, from PIF and milk powder processing plants in order to up-date those earlier studies by speciating the strains and determining their sequence types. The profiles of Cronobacter spp. isolates before and after the raised concern over the microbiological content of PIF are also compared. This new information has been obtained to increase the understanding of the ecology and distribution of significant strains of the organism which 
may be used in the development of improved and targeted intervention strategies for the control of the organism in the dairy industry.

\section{Materials and Methods}

\section{Bacterial strains}

A total of 85 strains were analyzed in this study. This was composed of 20 available strains from Muytjens et al. (1988; Table 1), 52 strains from Craven et al. (2010; Table 2) and 13 strains from Jacobs et al. (2011; Table 3). The latter two strain sets were representatives of the pulsetypes described in the original publications. Further details of the strains are given in Tables 1 to 3.

\section{MLST and sequence analysis}

The DNA extraction and MLST protocol was performed as described by Joseph et al. (2012c). All allele profiles and ST assignments were in accordance with the open access, curated database entries at http://www.pubmlst.org/cronobacter. Phylogenetic analysis of the concatenated sequences of the seven loci (3036 nucleotides concatenated length) was performed using the Maximum-Likelihood algorithm in MEGA 5, with 1000 bootstrap replicates (Tamura et al., 2011).

\section{Results}

A total of 85 strains were genotyped by MLST, and submitted to the pubMLST.org/cronobacter database. The majority $(n=72)$ of strains were identified as $C$. sakazakii, followed by $C$. turicensis $(n=9), C$. malonaticus $(n=3), C$. muytjensii $(n=1)$. No strains of $C$. dublinensis, $C$. universalis or $C$. condimenti were identified. Details of the Cronobacter spp. sequence type profiles are given in Tables 1 to 3 , and are summarized in Table 4. In addition, one strain from India was re- identified as E. hormaechei. The phylogenetic tree based on the concatenated 7 loci of MLST sequences (Fig 1) shows clear clustering across the Cronobacter genus with the 85 strains in four out of the seven species, 
160

161

162

163

164

165

166

167

168

169

170

171

172

173

174

175

176

177

178

179

180

181

182

183

184

185

186

187

and also the predominance of $C$. sakazakii ST4 and ST1 strains. The tree also shows the relatedness between the sequence types.

The older strain collection (Muytjens et al., 1988) was comprised of $C$. sakazakii (17/20), $C$. malonaticus $(2 / 20)$, and $C$. muytjensii $(1 / 20)$ (Table 1$)$. These strains had been isolated from PIF produced from Australia, Belgium, Canada, Denmark, France, Germany, New Zealand, Russia, The Netherlands, Uruguay and USA (Table 1). Five out of 17 of the $C$. sakazakii isolates were $C$. sakazakii ST4 strains. These had been isolated from PIF samples purchased in Canada, Russia, West Germany and The Netherlands. Three strains of $C$. sakazakii ST1 were isolated from PIF from The Netherlands and Russia, and two strains of $C$. sakazakii ST3 were from products from Belgium and The Netherlands. One E. hormaechei strain, previously identified as E. sakazakii, was also identified and had been isolated from PIF purchased in India.

The Australian strains (Craven et al., 2010) were primarily comprised of C. sakazakii (42/52), followed by $C$. turicensis (9/52) and $C$. malonaticus (1/52)(Table 2). The $C$. sakazakii strains were different pulsetypes of 116 isolates from 5 milk processing factories. Twelve of these pulsetype representatives were $C$. sakazakii ST4. The $C$. sakazakii ST4 strains had been isolated between 2006-2007, from various locations of all five sampled manufacturing plants; tanker bay, factory roofs, milk powder processing environment and outside grounds. Two isolates of $C$. sakazakii ST97 were from a tanker bay at one factory. This ST is within clonal complex 4, differing by 1 nucleotide (position 321, G:A) in the gltB allele from the ST4 profile. The close relatedness between ST4 and ST97 is also shown in the phylogenetic tree; Figure 1. The $C$. sakazakii ST1 strains represented 9 pulsetypes which comprised of 33 isolates. These had been isolated from similar milk powder manufacturing areas in $3 / 5$ factories sampled (Table 2). Two strains which could not be profiled using PFGE were $C$. sakazakii STs 3 and 133. A third strain which also could not be profiled using PFGE was $C$. turicensis ST132.

The original study by Jacobs et al. (2011) isolated 81 E. sakazakii isolates from one German manufacturing plant, and these were divided into 13 pulsetypes. In our study, all representative strains of these pulsetypes were identified as $C$. sakazakii (Table 3). The strains were primarily in ST1 $(n=4)$, ST4 $(n=3)$ and ST99 $(n=4)$. The C. sakazakii ST1 strains were isolated from a roller dryer which had been sampled in 2009. The $C$. sakazakii ST4 
strains were isolated from a roller dryer (sampled in 2009), and from a drying tower in 2006. The $C$. sakazakii ST99 strains had been collected from the filter powder and routine testing from two towers in 2006. Additionally, one strain (1530) was ST101. This sequence type is in clonal complex 10 with ST99; differing in one nucleotide of the fusA allele (position 378, G:A). The close relatedness of ST99 and ST101 is shown in Figure 1. Strain 1530 (ST101) had been isolated from filter powder collected from the same drying tower as had some of the closely related ST99 strains.

Across the three collections, the majority (28/39) of STs were identified in C. sakazakii compared to only 11 in $C$. malonaticus, $C$. turicensis and $C$. muytjensii. The main $C$. sakazakii STs were ST4 (24\%), ST1 (19\%), ST40 (5\%), ST99 (5\%) and ST3 (5\%); Table 4. C. sakazakii ST1 and ST4 were the only STs isolated from all three collections.

\section{Discussion}

A total of 85 strains of Cronobacter spp., which had only been identified as E. sakazakii in previous publications, were genotyped by MLST. The majority ( $85 \%$ ) of Cronobacter spp. isolates in the three strain collections were $C$. sakazakii, and included strains which could not be profiled using PFGE. The remaining strains were $C$. turicensis $(10 \%)$, C. malonaticus (4\%), and C. muytjensii (1\%). This corresponds with the predominance of $C$. sakazakii in neonatal infections and the few cases associated with $C$. turicensis and $C$. malonaticus (Hariri et al., 2012; Kucerova et al., 2011). To date, no neonatal infections have been attributed to $C$. muytjensii, $C$. dublinensis, $C$. universalis or $C$. condimenti. The latter three species were not identified from any of the three strain collections.

In the study of Muytjens et al. (1988), 50 strains had been isolated from PIF sourced from 35 different countries. They represent strains isolated before the international concern of neonatal infections through reconstituted infant formula which led to changes in the Codex Alimentarius Commission (2008) microbiological guidelines for PIF manufacturers. However, not all the strains in the Muytjens et al. (1988) study were Cronobacter species. A previous publication had shown that one strain identified as $E$. sakazakii from PIF from The Netherlands was E. hormaechei (Townsend et al., 2008). In this study, one strain isolated from PIF in India was also re-identified as E. hormaechei. The remaining Cronobacter spp. 
strains were identified as $C$. sakazakii $(17 / 20)$, . malonaticus $(2 / 20)$ and $C$. muytjensii $(1 / 20)$ (Table 1). Despite the presence of $C$. sakazakii ST4 in PIF samples, it should be noted that Muytjens et al. (1988) reported that no sample contained the organism at levels $>1$ cell $\mathrm{g}^{-1}$. Therefore good hygienic practices in the preparation of formula feeds should be used to reduce bacterial multiplication and risk of infection (FAO/WHO, 2006, 2008). It can be seen from table 4 that the main sequence types were $C$. sakazakii ST4 (20/85 isolates) and ST1 (16/85 strains). The former value slightly increases when including the single locus variant (ST97) in clonal complex 4 (21/85)(Table 4). This predominance of $C$. sakazakii in dairy factory environments matches investigations of previous Cronobacter spp. infections and outbreaks. C. sakazakii clonal complex 4, including ST4, is the predominant lineage of Cronobacter spp. associated with cases of neonatal meningitis (Hariri et al. 2012; Joseph et al., 2011). Furthermore, in the Cronobacter MLST database (http://www.pubMLST.org/cronobacter), more than one third of all the C. sakazakii isolates, isolated over a 50 year period, belong to these sequence types (Joseph et al., 2012c). The results of this study demonstrate that $C$. sakazakii ST4 can be present in the environment of milk powder factories such as tanker bay, shoes, roof, roller-dryer, spray-drying area and milk powder.

MLST and PFGE are genotyping techniques which can be applied to Cronobacter spp. isolates, although not all strains give PFGE profiles (Craven et al., 2010). No restriction site for $X b a l$ lies within the 7 alleles sequenced and therefore the allele sequences are independent of the PFGE methods used by Craven et al. (2010) and Jacobs et al. (2011). MLST discriminates at the level of one nucleotide in 3036 total sequenced bases, and can be used for phylogenetic construction (Joseph \& Forsythe, 2012; Joseph et al., 2012c). Figure 1 shows the overall diversity of the Cronobacter genus and that the majority of isolates were in a few STs of $C$. sakazakii. The figure also shows the close similarity between certain STs. For example, clonal complex 6 (ST40, ST45 and ST105) comprises of STs that differ by one locus. It is of note that the dominant $C$. sakazakii STs, ST1 and ST4, are not closely 'related' according to this figure, and this has been confirmed by whole genome sequencing (Joseph et al., 2012b). The reason for their predominance in strains collected over a 20 year period from around the world is unknown. The two sequence types also differ in that $C$. sakazakii ST4 is more associated with neonatal meningitis, whereas $C$. sakazakii ST1 is less commonly 
associated with clinical isolates (Joseph \& Forsythe, 2011). Nevertheless, severe clinical infections of neonates by $C$. sakazakii ST1 do occur. The most well-known was an outbreak in a neonatal intensive care unit in Tennessee (USA) which was reported by Himelright et al. (2002). The isolate (strain ATCC BAA-894, ST1) from the associated formula has been genome sequenced (Kucerova et al., 2010, 2011).

\section{Acknowledgements}

The authors thank the Ministry of Higher Education, Saudi and Nottingham Trent University for their financial support of this study. They also thank Harry Muytjens and Philipp Hammer for the provision of their strains for MLST profiling, and other contributors to the www.pubMLST.org/cronobacter database.

\section{References}

Arku, B., Mullane, N., Fox, E., Fanning, S., \& Jordan, K. (2008). Enterobacter sakazakii survives spray drying. International Journal of Dairy Technology, 61, 102-108.

Baldwin, A., Loughlin, M., Caubilla-Barron, J., Kucerova, E., Manning, G., Dowson, C., \& Forsythe, S. (2009). Multilocus sequence typing of Cronobacter sakazakii and Cronobacter malonaticus reveals stable clonal structures with clinical significance which do not correlate with biotypes. BioMed Central Microbiology, 9, 223.

Bowen, A.B., \& Braden, C.R. (2006). Invasive Enterobacter sakazakii disease in infants. Emerging Infectious Diseases, 12, 1185-1189.

Breeuwer, P., Lardeau, A., Peterz, M., \& Joosten, H.M. (2003). Desiccation and heat tolerance of Enterobacter sakazakii. Journal of Applied Microbiology, 95, 967-973. Caubilla-Barron, J., \& Forsythe, S. (2007). Dry stress and survival time of Enterobacter sakazakii and other Enterobacteriaceae. Journal of Food Protection, 70, 2111-2117. Caubilla-Barron, J., Hurrell, E., Townsend, S., Cheetham, P., Loc-Carrillo, C., Fayet, O., Prére, M.F., \& Forsythe, S.J. (2007). Genotypic and phenotypic analysis of Enterobacter sakazakii strains from an outbreak resulting in fatalities in a neonatal intensive care unit in France. Journal of Clinical Microbiology, 45, 3979-3985. 
Centers for Disease Control and Prevention. (2012). CDC Update: investigation of Cronobacter infections among infants in the United States. http://www.cdc.gov/foodsafety/diseases/cronobacter/investigation.html Codex Alimentarius Commission. (2008). Code of hygienic practice for powdered formulae for infants and young children. CAC/RCP 66-2008. Available at http://www.codexalimentarius.net/download/standards/11026/CXP_066e.pdf. Cordier, J-L. (2008). Production of powdered infant formulae and microbiological control measures. In 'Emerging issues in food safety. Enterobacter sakazakii'. Chapter 6. Farber JM, Forsythe SJ (ed) ASM Press, Washington, USA.

Craven, H.M., McAuley, C.M., Duffy, L.L., \& Fegan, N. (2010). Distribution, prevalence and persistence of Cronobacter (Enterobacter sakazakii) in the nonprocessing and processing environments of five milk powder factories. Journal of Applied Microbiology, 109, 10441052.

FAO/WHO. (2004). Workshop on Enterobacter sakazakii and other microorganisms in powdered infant formula. Geneva. Available at http://www.who.int/foodsafety/micro/jemra/meetings/feb2004/en/index.html FAO/WHO. (2006). Expert meeting on Enterobacter sakazakii and Salmonella in powdered infant formula. Rome. Available at http://www.who.int/foodsafety/micro/jemra/meetings/jan2006/en/index.html FAO/WHO. (2008). Enterobacter sakazakii (Cronobacter spp.) in powdered follow-up formulae. Microbiological Risk Assessment Series No. 15, Washington. Available at http://www.who.int/foodsafety/publications/micro/mra_followup/en/ Forsythe, S.J. (2005). Enterobacter sakazakii and other bacteria in powdered infant milk formula. Maternal and Child Nutrition, 1, 44-50. Hariri, S., Joseph, S., \& Forsythe, S.J. (2012). Predominance of Cronobacter sakazakii ST4 clonal complex strains in Cronobacter neonatal meningitis infections in US 2011. Emerging and Infectious Diseases. In Press.

Himelright, I., Harris, E., Lorch, V., \& Anderson, M. (2002). Enterobacter sakazakii infections associated with the use of powdered infant formula -Tennessee, 2001. Journal of the American Medicine Association, 287, 2204-2205. 
314 Hurrell, E., Kucerova, E., Loughlin, M., Caubilla-Barron, J., Hilton, A., Armstrong, R., Smith, C.,

315 Grant, J., Shoo, S., \& Forsythe, S. (2009). Neonatal enteral feeding tubes as loci for colonisation by members of the Enterobacteriaceae. BioMed Central Infectious Disease, 9 , 146 Iversen, C., \& Forsythe, S.J. (2003). Risk profile of Enterobacter sakazakii, an emergent pathogen associated with infant milk formula. Trends in Food Science and Technology, 14, $443-454$. Iversen, C., Lehner, A., Mullane, N., Bidlas, E., Cleenwerck, I., Marugg, J., Fanning, S., Stephan, R., \& Joosten, H. ( 2007). The taxonomy of Enterobacter sakazakii: proposal of a new genus Cronobacter gen. nov. and descriptions of Cronobacter sakazakii comb. nov. Cronobacter sakazakii subsp. sakazakii, comb. nov., Cronobacter sakazakii subsp. malonaticus subsp. nov., Cronobacter turicensis sp. nov., Cronobacter muytjensii sp. nov., Cronobacter dublinensis sp. nov. and Cronobacter genomospecies 1. BioMed Central Evolutionary Biology, 7, 64 . Jacobs, C., Braun, P., \& Hammer P. (2011). Reservoir and routes of transmission of Enterobacter sakazakii (Cronobacter spp.) in a milk powder-producing plant. Journal of Dairy Science, 94, 3801-3810. Joseph, S., \& Forsythe, S.J. (2011). Predominance of Cronobacter sakazakii sequence type 4 in neonatal Infections. Emerging and Infectious Disease, 17, 1713-1715. Joseph, S., \& Forsythe, S.J. (2012) Insights into the emergent bacterial pathogen Cronobacter spp., generated by multilocus sequence typing and analysis. Frontiers in Food Microbiology. 3, 397. Joseph, S., Cetinkaya, E., Drahovska, H., Levican, A., Figueras, M., \& Forsythe, S.J. (2012a). Cronobacter condimenti, sp. nov., isolated from spiced meat and Cronobacter universalis sp. nov., a novel species designation for Cronobacter sp. genomospecies 1, recovered from a leg infection, water, and food ingredients. International Journal of Systematic and Evolutionary Microbiology, 62, 1277-1283. Joseph, S., Desai, P., Li, Y., Cummings, C.A., Shih, R., Degoricija, L., Rico, A., Brzoska, P., 342 Hamby, S.E., Masood, N., Hariri, S., Sonbol, H., Chuzhanova, N., McClelland, M., Furtado, M.R., \& Forsythe S.J. (2012b) Comparative analysis of genome sequences covering the seven Cronobacter species. PLOS ONE 7(11): e49455 . 
Joseph, S., Sonbol, H., Hariri, S., Desai, P., McClelland, M., \& Forsythe, S.J. (2012c).

Diversity of the Cronobacter genus as revealed by multi locus sequence typing. Journal of Clinical Microbiology, 50, 3031-3039.

Kucerova, E., Clifton, S.W., Xia, X.Q., Long, F., Porwollik, S., Fulton, L., Fronick, C., Minx, P., Kyung, K., Warren, W., Fulton, R., Feng, D., Wollam, A., Shah, N., Bhonagiri, V., Nash, W.E., Hallsworth-Pepin, K., Wilson, R.K., McClelland, M., \& Forsythe, S.J. (2010). Genome sequence of Cronobacter sakazakii BAA-894 and comparative genomic hybridization analysis with other Cronobacter species. PLOS ONE, 5, e9556.

Kucerova, E., Joseph, S., \& Forsythe, S. (2011). The Cronobacter genus: ubiquity and diversity. Quality Assurance and Safety of Crops and Foods, 3, 104-122.

Lai, K.K. (2001). Enterobacter sakazakii infections among neonates, infants, children, and adults. Medicine, $80,113-122$.

Mullane, N.R., Whyte, P., Wall, P.G., Quinn, T., \& Fanning, S. (2007). Application of pulsedfield gel electrophoresis to characterise and trace the prevalence of Enterobacter sakazakii in an infant formula processing facility. International Journal Food Microbiology, 116, 73-81. Muytjens, H.L., Zanen, H.C., Sonderkamp, H.J., Kollee, L.A., Wachsmuth, I.K. and Farmer, J.J. IIIrd. 1983. Analysis of eight cases of neonatal meningitis and sepsis due to Enterobacter sakazakii. Journal of Clinical Microbiology, 18, 115-120. Muytjens, H.L., van Der Ros-van de Repe, J., \& van Druten, H.A. (1984). Enzymatic profiles of Enterobacter sakazakii and related species with special reference to the alpha-glucosidase reaction and reproducibility of the test system. Journal of Clinical Microbiology, 20, 684686.

Muytjens, H.L., Roelofs-Willemse, H., \& Jaspar, G.H. (1988). Quality of powdered substitutes for breast milk with regard to members of the family Enterobacteriaceae. Journal of Clinical Microbiology, 26, 743-746.

Osaili, T., \& Forsythe, S. (2009). Desiccation resistance and persistence of Cronobacter species in infant formula. International Journal of Food Microbiology, 136, 214-220.

Tamura, K, Peterson, D., Peterson, N., Stecher, G., \& Nei, M. (2011). MEGA5: molecular evolutionary genetics analysis using maximum likelihood, evolutionary distance, and maximum parsimony methods. Molecular Biology and Evolution, 28, 2731-2739. 
375 Townsend, S.M., Hurrell, E., Caubilla-Barron, J., Loc-Carrillo, C., \& Forsythe, S.J. 376 (2008). Characterization of an extended-spectrum beta-lactamase Enterobacter 377 hormaechei nosocomial outbreak, and other Enterobacter hormaechei misidentified 378 as Cronobacter (Enterobacter) sakazakii. Microbiology, 154, 3659-3667.

379 van Acker, J., de Smet, F., Muyldermans, G., Bougatef, A., \& Naessens, A. (2001). Outbreak 380 of necrotizing enterocolitis associated with Enterobacter sakazakii in powdered milk 381 formula. Journal of Clinical Microbiology, 39, 293-297.

382

383 
Figure 1.

385

386

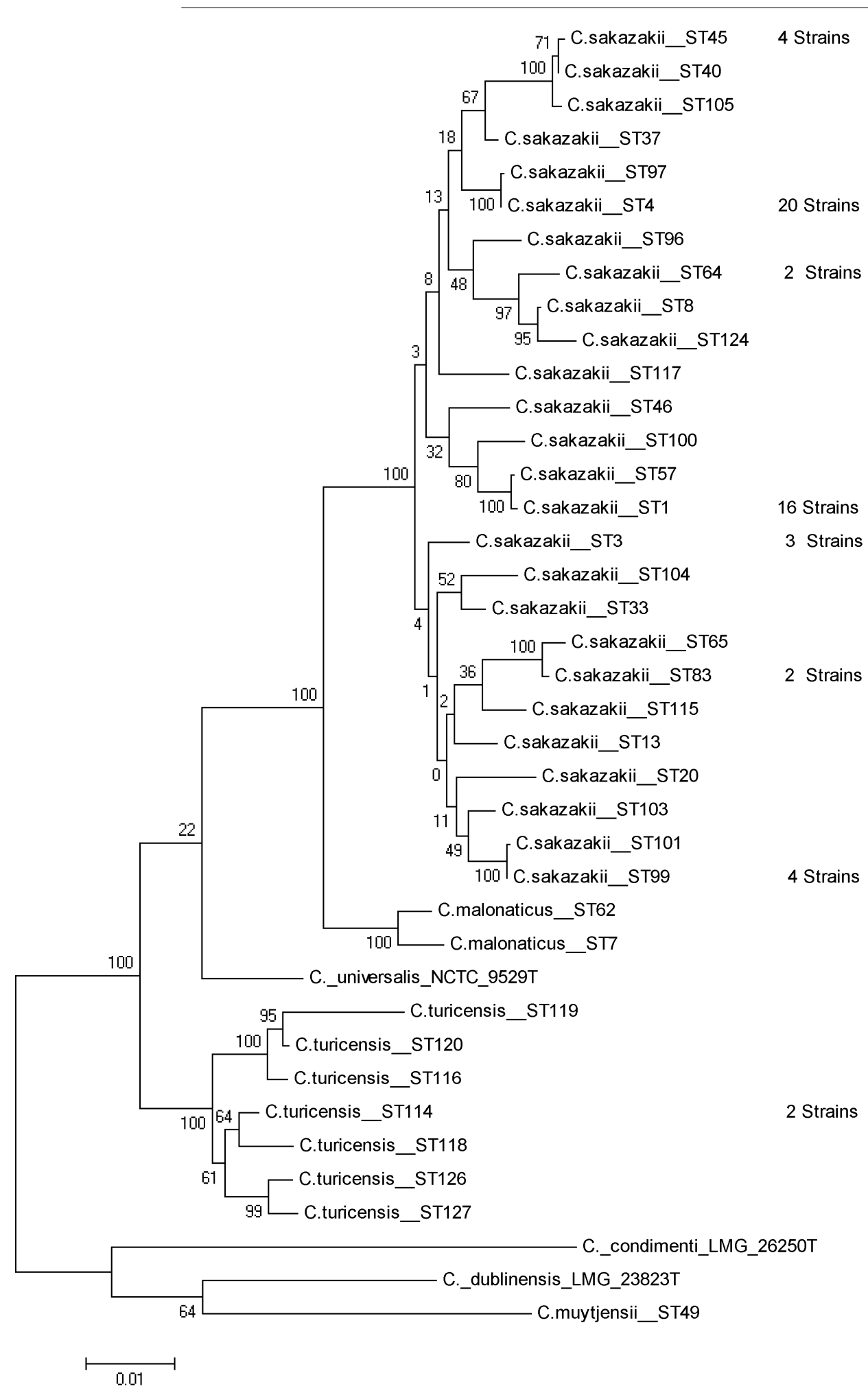


Table 1 Multilocus sequence typing profiles of Cronobacter strains isolated from powdered infant formula, and reported by Muytjens et al. (1988)

\begin{tabular}{|c|c|c|c|c|}
\hline Bacterial species & $\mathrm{ST}^{\mathrm{a}}$ & Clonal complex & $I D^{c}$ & Country \\
\hline \multirow[t]{17}{*}{ C. sakazakii } & 1 & 1 & 541 & The Netherlands \\
\hline & 1 & 1 & 543 & The Netherlands \\
\hline & 1 & 1 & 537 & Russia \\
\hline & 3 & & 528 & Belgium \\
\hline & 3 & & 545 & The Netherlands \\
\hline & 4 & 4 & 529 & Canada \\
\hline & 4 & 4 & 538 & Russia \\
\hline & 4 & 4 & 540 & The Netherlands \\
\hline & 4 & 4 & 544 & The Netherlands \\
\hline & 4 & 4 & 548 & West Germany \\
\hline & 8 & 15 & HPB-3284 & Uruguay \\
\hline & 124 & 15 & 539 & The Netherlands \\
\hline & 13 & 8 & 532 & East Germany \\
\hline & 45 & 6 & 536 & Russia \\
\hline & 65 & 9 & 547 & USA \\
\hline & 57 & & 531 & Denmark \\
\hline & 64 & & 533 & France \\
\hline \multirow[t]{2}{*}{ C. malonaticus } & 7 & 2 & 535 & New Zealand \\
\hline & 62 & & 527 & Australia \\
\hline C. muytjensii & 49 & & 530 & Denmark \\
\hline
\end{tabular}


390 a ST=Sequence type

391 b Clonal complex defined as clusters of sequence types with single locus variants, as given by Joseph et al. (2012b).

392 c Strain identification code

393 d Multilocus sequence type profile deposited in http://www.pubMLST.org.cronobacter database by other collaborators. 
Table 2 Multilocus sequence typing profiles of Cronobacter strains isolated from five milk powder manufacturing plants in Australia between 2006-2007, 396 and reported by Craven et al. (2010).

\begin{tabular}{|c|c|c|c|c|c|c|c|}
\hline Cronobacter species & $\mathrm{ST}^{\mathrm{a}}$ & Clonal complex ${ }^{\mathrm{b}}$ & $\mathrm{ID}^{\mathrm{c}}$ & Isolation environment & Pulsetype & $\begin{array}{c}\text { Number of } \\
\text { isolates }\end{array}$ & Factory \\
\hline \multirow[t]{25}{*}{ C. sakazakii } & 1 & 1 & 1466 & Milk powder & 1 & 5 & $\mathrm{~B}$ \\
\hline & 1 & 1 & 1479 & Milk powder & 14 & 1 & C \\
\hline & 1 & 1 & 1492 & Roof, milk powder & 27 & 12 & $\mathrm{~B}$ \\
\hline & 1 & 1 & 1493 & Other processing (butter) & 28 & 1 & $\mathrm{~B}$ \\
\hline & 1 & 1 & 1494 & Tanker bay, milk powder & 29 & 3 & $E$ \\
\hline & 1 & 1 & 1495 & Milk powder & 30 & 7 & E \\
\hline & 1 & 1 & 1496 & Milk powder & 31 & 1 & $E$ \\
\hline & 1 & 1 & 1499 & Milk powder & 34 & 1 & $\mathrm{~B}$ \\
\hline & 1 & 1 & 1502 & Roof & 37 & 2 & $\mathrm{C}$ \\
\hline & 117 & 1 & 1497 & Milk powder & 32 & 8 & $A$ \\
\hline & 3 & & 1503 & Tanker bay & 38 & 1 & $\mathrm{C}$ \\
\hline & 3 & & 1899 & Tanker bay & $N P^{d}$ & 1 & $\mathrm{C}$ \\
\hline & 4 & 4 & 1476 & $\begin{array}{l}\text { Milk powder, other processing (evaporator), } \\
\text { other processing }\end{array}$ & 11 & 6 & $B, E$ \\
\hline & 4 & 4 & 1477 & Roof, milk powder & 12 & 7 & $\mathrm{~B}$ \\
\hline & 4 & 4 & 1480 & Milk powder & 15 & 4 & $A, D$ \\
\hline & 4 & 4 & 1481 & Other processing (evaporator) & 16 & 1 & $A$ \\
\hline & 4 & 4 & 1482 & Tanker bay & 17 & 1 & $A$ \\
\hline & 4 & 4 & 1483 & Milk powder & 18 & 1 & $\mathrm{D}$ \\
\hline & 4 & 4 & 1484 & Roof, milk powder & 19 & 4 & $C, E$ \\
\hline & 4 & 4 & 1485 & Other external (outside grounds) & 20 & 1 & $\mathrm{C}$ \\
\hline & 4 & 4 & 1486 & Other external (outside grounds) & 21 & 1 & $\mathrm{C}$ \\
\hline & 4 & 4 & 1487 & Tanker bay & 22 & 1 & $A$ \\
\hline & 4 & 4 & 1488 & Milk powder & 23 & 1 & $\mathrm{D}$ \\
\hline & 4 & 4 & 1489 & Milk powder & 24 & 2 & $A$ \\
\hline & 97 & 4 & 1490 & Tanker bay & 25 & 2 & $\mathrm{~B}$ \\
\hline
\end{tabular}




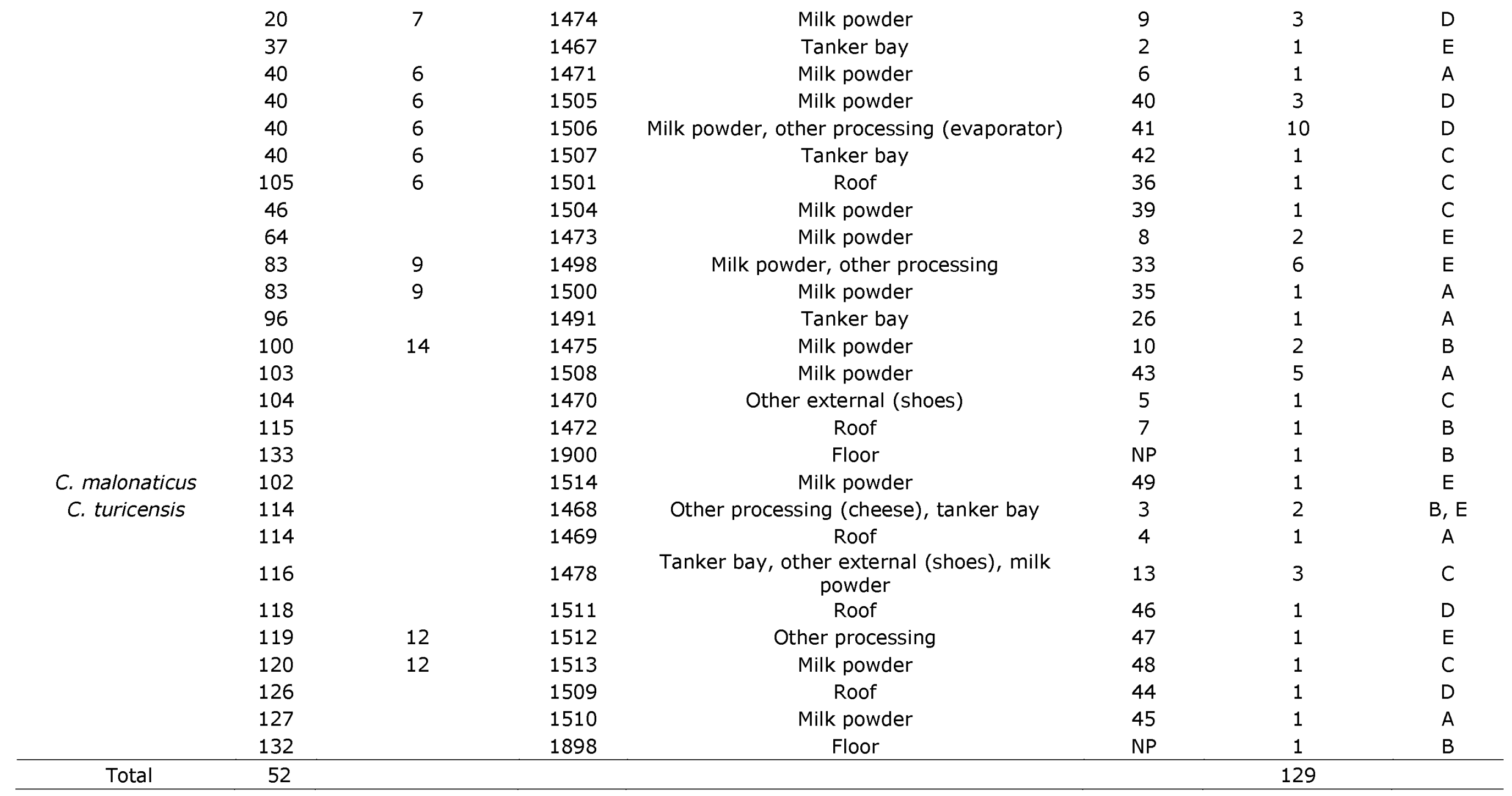


399 b Clonal complex defined as clusters of sequence types with single locus variants, as given by Joseph et al. (2012b).

$400 \quad$ c ID $=$ Strain identification code

$401 \mathrm{~d}$ NP $=$ No profile obtained from PFGE 
Table 3 Multilocus sequence typing profiles of Cronobacter strains isolated from a milk powder manufacturing plant in Germany in 2006 and 2009 , and 405 reported by Jacobs et al. (2011).

406

\begin{tabular}{|c|c|c|c|c|c|c|c|}
\hline $\begin{array}{c}\text { Cronobacter } \\
\text { species }\end{array}$ & $\mathrm{ST}^{\mathrm{a}}$ & Clonal complex ${ }^{\mathrm{b}}$ & $\mathrm{ID}^{\mathrm{c}}$ & Source & Year & Pulsetype $^{\mathrm{d}}$ & $\begin{array}{c}\text { Number of } \\
\text { isolates }\end{array}$ \\
\hline \multirow[t]{13}{*}{ C. sakazakii } & 1 & 1 & 1536 & Roller Dryer (conc.) & 2009 & $2009-2$ & 2 \\
\hline & 1 & 1 & 1538 & Roller Dryer (conc.) & 2009 & $2009-1$ & 2 \\
\hline & 1 & 1 & 1540 & Roller Dryer (powder) & 2009 & $2009-3$ & 1 \\
\hline & 1 & 1 & 1541 & Roller Dryer (powder) & 2009 & $2009-4$ & 2 \\
\hline & 4 & 4 & 1537 & Roller Dryer (powder) & 2009 & $2009-5$ & 10 \\
\hline & 4 & 4 & 1542 & Roller Dryer (conc.) & 2009 & $2009-6$ & 7 \\
\hline & 4 & 4 & 1533 & Drying tower 1 (environment) & 2006 & $2006-6$ & 2 \\
\hline & 33 & & 1534 & Drying tower 1 (environment) & 2006 & $2006-7$ & 1 \\
\hline & 99 & 10 & 1529 & Drying tower $1(\mathrm{MTA})^{\mathrm{e}}$ & 2006 & $2006-3$ & 1 \\
\hline & 99 & 10 & 1531 & Drying tower 1 (filter powder) & 2006 & 2006-1 & 14 \\
\hline & 99 & 10 & 1532 & Drying tower 2 (filter powder) & 2006 & $2006-5$ & 2 \\
\hline & 99 & 10 & 1535 & Drying tower 1 (MTA) & 2006 & $2006-2$ & 29 \\
\hline & 101 & 10 & 1530 & Drying tower 2 (filter powder) & 2006 & $2006-4$ & 8 \\
\hline Total & 13 & & & & & & 81 \\
\hline
\end{tabular}

407

408 a ST= Sequence type

409 b Clonal complex defined as clusters of sequence types with single locus variants, as given by Joseph et al. (2012b).

$410 \quad$ c ID $=$ Strain identification code

$411 \mathrm{~d}$ Note, same pulsetype numbers for strains isolated in 2006 and 2009 do not reflect any similarity. 
e MTA = microbiological trend analysis (from final products).

413 
415

416

Table 4 Multilocus sequence typing profiles of 85 Cronobacter strains collected between 1988 and 2009.

417

\begin{tabular}{|c|c|c|c|c|c|c|}
\hline \multirow{2}{*}{ Bacterial species } & \multirow{2}{*}{$\begin{array}{l}\text { Sequence type (clonal } \\
\text { complex })^{\mathrm{a}}\end{array}$} & \multicolumn{3}{|c|}{ Number of strains } & \multirow{2}{*}{$\begin{array}{l}\text { Total of } \\
\text { strains }\end{array}$} & \multirow{2}{*}{$\begin{array}{l}\text { Percentag } \\
\text { (\%) }\end{array}$} \\
\hline & & Muytjens et al. (1988) & Craven et al. (2010) & Jacobs et al. (2011) & & \\
\hline \multirow[t]{13}{*}{ C. sakazakii } & & 17 & 42 & 13 & 72 & 85 \\
\hline & $4(4)$ & 5 & 12 & 3 & 20 & 24 \\
\hline & $97(4)$ & 0 & 1 & 0 & 1 & 1 \\
\hline & $1(1)$ & 3 & 9 & 4 & 16 & 19 \\
\hline & 117 & 0 & 1 & 0 & 1 & 1 \\
\hline & $40(6)$ & 0 & 4 & 0 & 4 & 5 \\
\hline & $105(6)$ & 0 & 1 & 0 & 1 & 1 \\
\hline & $99(10)$ & 0 & 0 & 4 & 4 & 5 \\
\hline & $101(10)$ & 0 & 0 & 1 & 1 & 1 \\
\hline & 3 & 2 & 2 & 0 & 4 & 5 \\
\hline & $8(15)$ & 1 & 0 & 0 & 1 & 1 \\
\hline & $124(15)$ & 1 & 0 & 0 & 1 & 1 \\
\hline & Others & 5 & 12 & 1 & 18 & 21 \\
\hline C. turicensis & $\begin{array}{c}114,116,118,119 \\
120,126,127\end{array}$ & 0 & 9 & 0 & 9 & 10 \\
\hline C. malonaticus & $7,62,102$ & 2 & 1 & 0 & 3 & 4 \\
\hline C. muytjensii & 49 & 1 & 0 & 0 & 1 & 1 \\
\hline Total & & 20 & 52 & 13 & 85 & 100 \\
\hline
\end{tabular}


419

a Clonal complex defined as clusters of sequence types with single locus variants, as given by Joseph et al. (2012b).

420

421 
Figure 1. Maximum likelihood tree of the seven multilocus sequence typing loci (3036 base pair concatenated length) for the Cronobacter genus, showing the sequence type for isolated strains and type strains only for Cronobacter species not identified from the strain collections. The tree was drawn using MEGA5 (http://www.megasoftware.net/) with 1000 bootstrap replicates.

425

426 